University of Alaska Southeast

From the ScholarWorks@UA collection of Brian Buma

February 27, 2018

\title{
A foundation of ecology rediscovered: 100 years of succession on the William S. Cooper plots in Glacier Bay, Alaska
}

Brian Buma, Sara Bisbing, John Krapek, Glenn Wright

Originally published in: Buma, Brian, Sarah Bisbing, John Krapek, and Glenn Wright. "A foundation of ecology rediscovered: 100 years of succession on the William S. Cooper plots in Glacier Bay, Alaska." Ecology 98, no. 6 (2017): 1513-1523.

\section{ScholarWorks@UA}

Available at: https://scholarworks.alaska.edu/handle/11122/8170 


\title{
A foundation of ecology rediscovered: 100 years of succession on the William S. Cooper plots in Glacier Bay, Alaska
}

\author{
Brian Buma, ${ }^{1,5}$ Sarah Bisbing, ${ }^{2}$ John Krapek, ${ }^{3}$ and Glenn Wright ${ }^{4}$ \\ ${ }^{1}$ Department of Natural Sciences, School of Arts and Sciences, University of Alaska, Southeast, 11120 Glacier Highway, \\ Juneau, Alaska 99801 USA \\ ${ }^{2}$ Department of Natural Resources Management \& Environmental Sciences, California Polytechnic State University, \\ 1 Grand Avenue, San Luis Obispo, California 93407 USA \\ ${ }^{3}$ School of Natural Resources and Extension, University of Alaska, Fairbanks, 11120 Glacier Highway, Juneau, Alaska 99801 USA \\ ${ }^{4}$ Department of Social Science, School of Arts and Sciences, University of Alaska, Southeast, 11120 Glacier Highway, \\ Juneau, Alaska 99801 USA
}

\begin{abstract}
Understanding plant community succession is one of the original pursuits of ecology, forming some of the earliest theoretical frameworks in the field. Much of this was built on the long-term research of William S. Cooper, who established a permanent plot network in Glacier Bay, Alaska, in 1916. This study now represents the longest-running primary succession plot network in the world. Permanent plots are useful for their ability to follow mechanistic change through time without assumptions inherent in space-for-time (chronosequence) designs. After 100-yr, these plots show surprising variety in species composition, soil characteristics (carbon, nitrogen, depth), and percent cover, attributable to variation in initial vegetation establishment first noted by Cooper in the 1916-1923 time period, partially driven by dispersal limitations. There has been almost a complete community composition replacement over the century and general species richness increase, but the effective number of species has declined significantly due to dominance of Salix species which established 100-yr prior (the only remaining species from the original cohort). Where Salix dominates, there is no establishment of "later" successional species like Picea. Plots nearer the entrance to Glacier Bay, and thus closer to potential seed sources after the most recent glaciation, have had consistently higher species richness for $100 \mathrm{yr}$. Age of plots is the best predictor of soil $\mathrm{N}$ content and C:N ratio, though plots still dominated by Salix had lower overall N; soil accumulation was more associated with dominant species. This highlights the importance of contingency and dispersal in community development. The 100-yr record of these plots, including species composition, spatial relationships, cover, and observed interactions between species provides a powerful view of long-term primary succession.
\end{abstract}

Key words: chronosequence; community dynamics; glacial recession; permanent plot; primary succession; relay floristics; repeat survey; successional theory; vegetation development; William S. Cooper.

\section{INTRODUCTION}

Plant succession, as a field of study, is one of the oldest pursuits in ecology (Cowles 1901, 1911, Clements 1916, Gleason 1917, see Egerton 2015 review). The concept of succession was born out of the observation that temporal patterns in community organization are often predictable, recognized as early as Darwin (1859). Both primary succession (e.g., sand dune colonization, Cowles 1911) and secondary succession (e.g., old field succession, Billings 1938) have been studied for many decades, and, while approaches have become more sophisticated (e.g., resource ratios, Tilman 1985, soil biota-plant feedbacks, Castle et al. 2016), studies continue to explore the commonalities and differences between plant community assembly and development. With the rapid retreat

Manuscript received 14 October 2016; revised 16 March 2017; accepted 24 March 2017. Corresponding Editor: Pamela H. Templer.

${ }^{5}$ E-mail: bbuma@alaska.edu of glaciers (Shepherd et al. 2012), climate change extending plant ranges into higher latitudes (Pearson et al. 2013), and increasingly sophisticated experimental techniques (e.g., Castle et al. 2016), successional research is expanding its conceptual and quantitative understandings (Meiners et al. 2015), and finding utility in global change questions (Walker and Wardle 2014).

Given that succession and community change occurs at much longer time scales than typically observed, straightforward long-term plot monitoring networks are less common than indirect approaches, such as chronosequences (space-for-time substitutions; Walker et al. 2010). The difficulty with chronosequence research stems from the assumption that places separated in space (and therefore time, by design) are equivalent in terms of their starting conditions. This assumption has been questioned for decades (Egler 1954, Pickett 1989, Johnson and Miyanishi 2008), with the role of stochastic species assemblage, spatial effects, and priority effects identified as potential drivers of variation, confounding interpretations. Recent 
reviews have highlighted species composition and abundance as especially difficult to monitor with chronosequences, while suggesting that aggregate community metrics (richness, plant cover, and soil development) may be more stable within a given locality (Walker et al. 2010). Individual-scale metrics (e.g., species composition) are likely more dependent on initial community composition and stochastic variation early in the history of the plot (Egler 1954, Fastie 1995). While we have undoubtedly learned immense amounts from these inferential methods, it is also well understood that confirmation of lessons learned via those pathways requires monitoring single locations for long periods of time (e.g., Harmon and Pabst 2015). Thus, while difficult to maintain over multiple investigators and investigator life-spans, long-term permanent plot studies can be used to not only monitor change in individual locations but investigate the utility of chronosequences.

In 1916, William S. Cooper established a plot network within the recently deglaciated terrain of Glacier Bay, Alaska. He was attracted to the area because of the rapid retreat of the glaciers, the pristine nature of the terrain, and the detailed dates of retreat documented through accurate mapping by a number of researchers and visitors, starting with George Vancouver (sailing in 1794) through detailed records by John Muir (starting in 1879). Cooper, a student of pioneering plant ecologist Henry Cowles, was interested in how plant communities assembled. Cowles started with long-term monitoring on sand dunes in Michigan (Cowles 1899); Cooper expanded on Cowles' original concept of plant community organization and developed the foundation of primary succession ecology with repeat visits to Glacier Bay (described in Cooper 1923, 1931, 1939). Cooper counted, measured, and mapped individual plants, quantifying the demography and community ecology of the early successional community. The plots were established between 17 and $37 \mathrm{yr}$ after glacial retreat (Table 1) and have now been followed to present day, $100 \mathrm{yr}$ after establishment.
These plots represent, to our knowledge, the longest permanent, primary succession (post-glacial) plot network in the world and uniquely follow the development of a natural, untrammeled ecosystem from a bare, postglacial landscape. The entire region has been protected from human activity, first as a National Monument and later a National Park, since shortly after deglaciation. No settlements have occurred within $100 \mathrm{~km}$ of the plot locations, and it is likely that, with the exception of visits led by Cooper and subsequent periodic re-measurement by his student Donald B. Lawrence (until the 1980's), the original sampling locations have been entirely devoid of human presence due to the challenges imposed by terrain, travel distances, weather, and logistical difficulty. Cooper's original research on these locations forms the seminal research in successional ecology, a cornerstone of our environmental understanding today. After Lawrence's death, unfortunately, the plot locations were lost due to communication breakdowns with the next generation of caretakers. On the centennial of plot establishment, this work focused on (1) rediscovering the plot locations and permanently documenting their location for future study, (2) measuring community composition and soil development for comparison with the historical development as recorded from 1916 to 1941, (3) comparing results of permanent plots to inferential chronosequence methods, and (4) relating observed change to successional theory.

\section{Methods}

In June 2016, an expedition was undertaken to rediscover and re-measure Cooper's original plot network (Q1-8; Cooper 1923) in the West Arm of Glacier Bay National Park. After some difficulty, plots were rediscovered using the original compass directions from Cooper (1923), 1940's era landscape photographs (UM Lawrence archives), and notes from Cooper's original field notebooks that gave fragmentary pieces of directions to all eight of the plots (UM Cooper archives). Plot corners were originally marked with painted rocks (from

TABLE 1. Characteristics of William S. Cooper's original plots in Glacier Bay National Park, Alaska.

\begin{tabular}{lcccccc}
\hline \hline Plot & Exposure date & Slope $($ deg. $)$ & Aspect & Distance $(\mathrm{km})$ & Current canopy & Canopy cover $(\%)$ \\
\hline Q1 & 1879 & 9 & $\mathrm{~S}$ & 72 & Salix spp. & 85 \\
Q2 & 1879 & 16 & $\mathrm{SE}$ & 72 & Picea sitchensis & 90 \\
Q3 & 1879 & $\mathrm{NA}$ & $\mathrm{NA} \dagger$ & 72 & Salix spp. & 76 \\
Q4 & 1899 & 14 & $\mathrm{E}$ & 76 & Salix spp. & 47 \\
Q5 & 1899 & 0 & $\mathrm{NA}$ & 76 & Salix spp. & 38 \\
Q6 & 1899 & 22 & $\mathrm{E}$ & 76 & Salix spp. & 90 \\
Q7 & 1892 & 12 & $\mathrm{~S}$ & 45 & Alnus viridis & 86 \\
Q8 & 1892 & 4 & $\mathrm{~S}$ & 45 & A. viridis & 67 \\
Q9 & 1892 & & & & & \\
\hline
\end{tabular}

Notes: Slope is of the glacial till/gravel substrate as measured by Cooper in 1916. Distance refers to the approximate distance from unglaciated land at the height of the Little Ice Age, when observed by Vancouver (sailing in 1794).

$\dagger$ Missing from original 1916 field notes. Current soil surface is approximately $15^{\circ}$ slope and SE aspect.

Lost due to erosion. 
1916), followed by iron rods in rock cairns (from 1929) in all plots except plot one (Q1, marked with wire), making it possible to re-establish exact locations with a metal detector (Fig. 1). Following Cooper's original methods (Cooper 1923, 1939), each plot was photographed (Appendix S1: Fig. S1), sketch mapped, and percent coverage of all species were quantified. Historical data on species composition, number of individuals, and percent cover were obtained from published maps (Cooper 1923, 1931, 1939) and unpublished manuscripts (Lawrence 1948) for comparison with the 2016 results.

Hemispherical photographs were taken at $1 \mathrm{~m}$ to quantify canopy coverage. Photos were processed using Gap Light Analyzer (GLA) version 2.0 (Frazer et al. 1999) and adjusted for image orientation, geographic location (latitude/longitude), elevation, growing season length, and sampling time of year. Image pixels were separated into sky vs. foliage using the threshold procedure, and total light transmission, the fraction of light reaching the ground relative to the light above the canopy, was derived in GLA.

Three soil samples were taken on the downhill side of each plot within $20 \mathrm{~cm}$ of the plot edge. Detrital depth was noted, and soil depth down to the original glacial till measured. Individual samples were taken at each $5 \mathrm{~cm}$ deep increment within each core. Samples were kept cool until returned to the lab, at which point they were dried for $48 \mathrm{~h}$ at $70^{\circ} \mathrm{C}$, ground, and analyzed for $\mathrm{C}$ and $\mathrm{N}$ concentrations using a flash combustion elemental analyzer. To maintain consistency in samples between plots with differing soil depth, chemistry analyses reported here were limited to the top $5 \mathrm{~cm}$ of soil in each profile.

\section{Analyses}

We assessed species diversity per quadrat over time by calculating the Probability of Interspecific Encounters (PIE, Hurlbert 1971) and the Effective Number of Species (ENS, Jost 2006, Dauby and Hardy 2012, Chase and Knight 2013). Hurlbert's PIE quantifies the probability that two individuals randomly drawn from a community are of different species, with a low PIE indicating that few species dominate and a high PIE indicating community evenness. This metric quantifies the potential for randomness in species composition at different locations within a community (Hurlbert 1971). The ENS index is derived from PIE and provides the number of equally abundant species (i.e., perfectly abundant community) to achieve each associated PIE, where rare species represent a fraction of an effective species to explicitly account for their

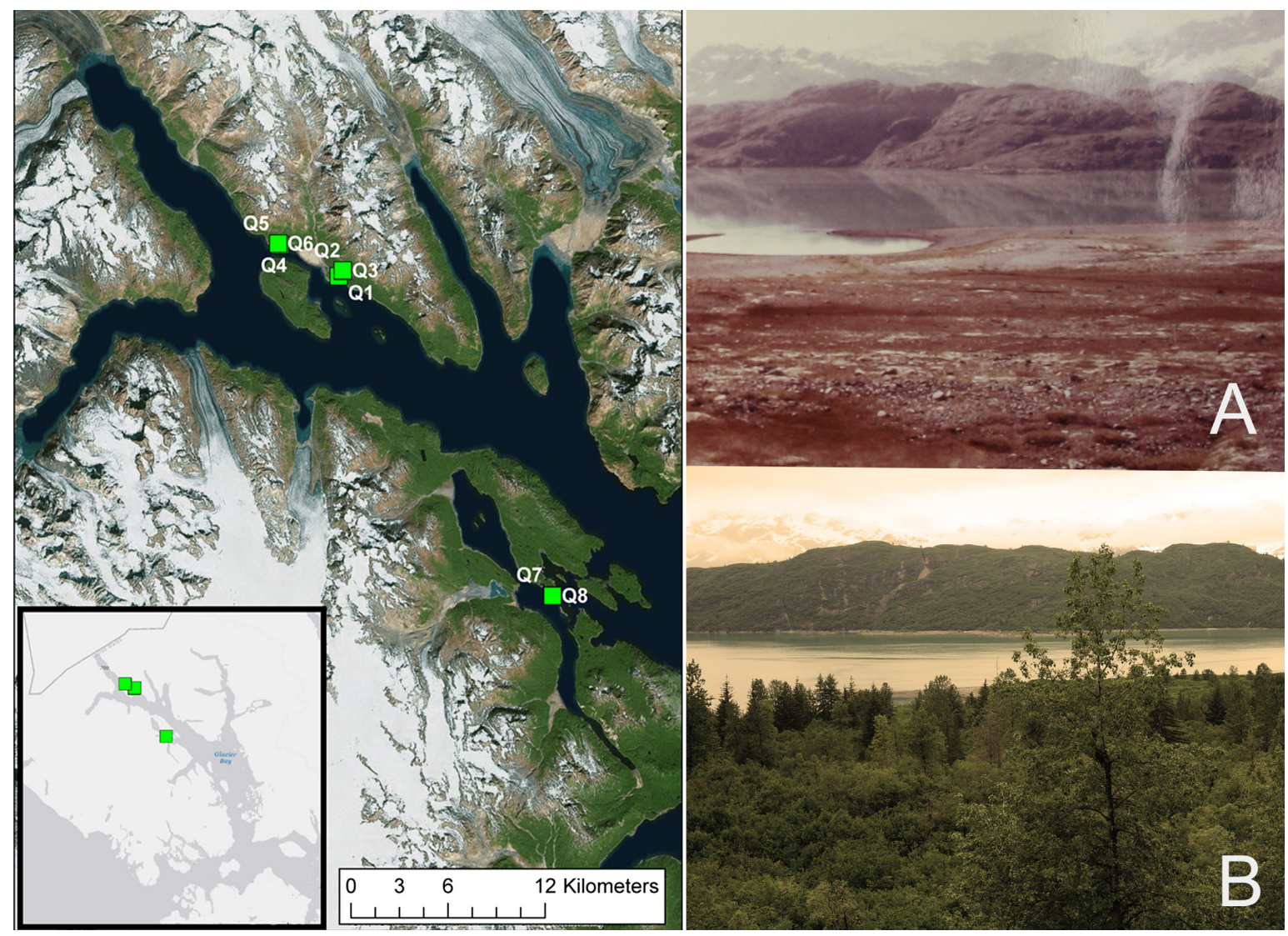

FIg. 1. Location of Cooper's 1916 plot network in Glacier Bay, Alaska. (A, B) View from Q3 towards Q1 in 1941 and 2016 , respectively. [Color figure can be viewed at wileyonlinelibrary.com] 
disproportionate effect on measures of species richness (Chase and Knight 2013). In a perfectly even community, ENS would equal the total number of species present in the community. Both PIE and ENS were chosen because they can be interpreted in a biologically meaningful way and are scale-independent (unlike richness; Jost 2006, Colwell 2009). While bryophyte species were identified to the species level, they were pooled to the genus level for analysis to align with the original datasets from Cooper and Lawrence (except where specifically noted).

Rarefaction analyses were performed to more accurately estimate the expected number of species found in a larger sample of the same assemblage and identify true richness (Gotelli and Colwell 2001, Colwell et al. 2004). Mao-Tau sample-based rarefaction and abundance-based coverage estimate (ACE) assessments were performed in EstimateS v. 9.1 (Colwell 2013). For each rarefaction, 100 random resamples were drawn without replacement from each quadrat sampled $\left(\mathrm{N}_{\text {samples }}=8\right)$ within each time step $\left(\mathrm{N}_{\text {time }}=6\right)$. It was necessary to pool plots into each field expedition for this analysis (e.g., the 1916 Cooper expedition, the 1921 Cooper expedition, etc.) rather than work from individual sampling plots. Therefore, species estimates from this method represent the landscape composition at a small range of plot ages post-glacial time.

All statistical analyses were done using either Spearman's $\rho$ for age-based comparisons or Mann-Whitney's $U$ for location-based comparisons where appropriate (plots were considered either near (Q7 and 8) or far (Q1-6) from seed sources, see Table 1 for distances).

\section{Results}

Herbaceous plants were the major component of the early post-glacial community, though sparse and somewhat rare (Cooper 1923). Epilobium latifolium, an early perennial pioneer, was the most important herb as of 1916, albeit with high turnover, behaving more like an annual (Cooper 1939). It rapidly diminished in importance, however, disappearing by 1929 , though it is still found on the shoreline under high-light, frequently disturbed conditions (Buma, personal observation).

Herbaceous plants generally gave way to mat forming plants approximately $40 \mathrm{yr}$ following exposure (Figs. 2,
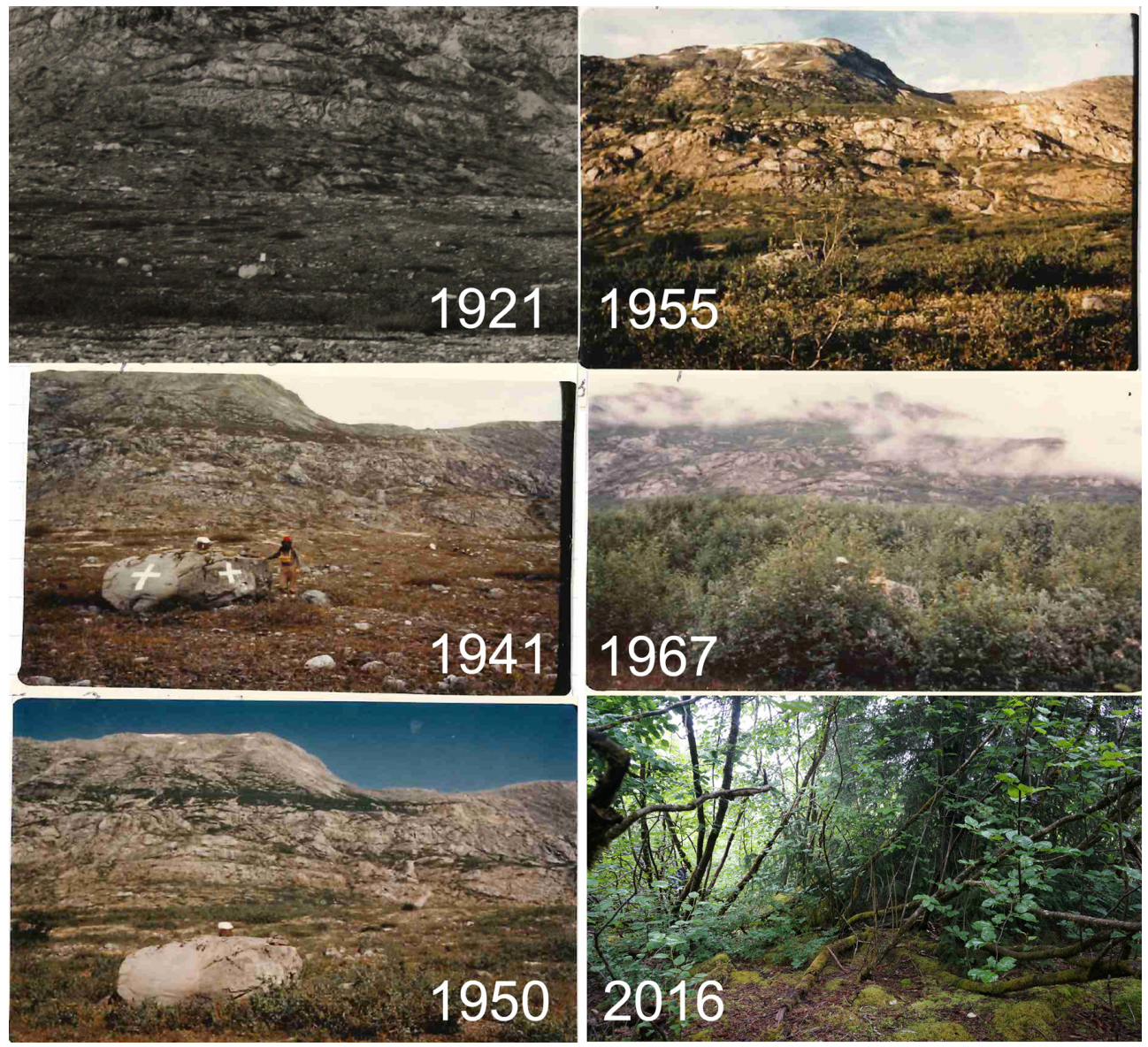

FIG. 2. "Cross Rock," the glacial erratic which formed the basis of Cooper's directions to Q1-3. Easily visible in the first $100 \mathrm{yr}$ of succession, it was completely obscured by 2016. All photos taken in similar location and facing the same direction, towards Q3 (east); the photographs in Fig. 1 are taken from the base of the hill in the background, facing towards Cross Rock and Q1. The 1921 date is estimated. [Color figure can be viewed at wileyonlinelibrary.com] 
3). These mat plants, predominately Dryas drummondii and Racomitrium spp. mosses, were recognized early on as very important to soil development. Early results described their mechanical function in retaining organic matter accumulations against erosional processes along with prostrate Salix stems (Cooper 1923, 1939) and Dryas' role in nitrogen fixation (Lawrence et al. 1967). Cooper also noted variation in erosional processes as driving establishment processes in the surrounding landscape (1931). A less appreciated at the time, but perhaps equally consequential, role of the mat plants may be partially inhibiting the establishment of competitively dominant Salix (see Canopy development, below). By 1941, the majority of the plots were entirely covered by mat plants (Appendix S1: Table S1), with Dryas comprising over 50\% of the total coverage (Appendix S1: Table S2). By $100 \mathrm{yr}$ post-exposure, the pioneering mat plants were almost completely replaced. In 1988, the entire original community was eliminated with the exception of Salix spp., "a few" Equisetum stems, and isolated Racomitrium spp. (D. B. Lawrence, unpublished letters). Over the subsequent two decades, the community continued to shift from an herbaceous- to shrub-dominated ecosystem, and, by 2016, all early pioneering species other than Salix were lost.

\section{Canopy development}

Woody plants currently dominate the canopy of all plots, but canopy composition varies considerably (Table 1; Appendix S1: Table S4). For the plots furthest up the bay, the canopy primarily consists of tall Salix species rooted within the plots and occassional coverage from an adjacent Picea sitchensis (Sitka spruce, Q2, first noted in 1972) or Alnus viridis var. sinuata (Sitka alder, partial coverage on Q1 and Q6). At the plots closest to the mouth of the bay, the canopy is exclusively Alnus. Salix established early in succession (present on all plots except Q2 in 1916), with erect stems first noted in 1929 (1 individual) and 1935 (10 individuals; Cooper 1939). Alnus arrived somewhat later, first noted in the 1930's in the general landscape and not noted to be rooting on any plots (Q8) until 1972 (D. B. Lawrence, unpublished data). Despite the expectation that the early colonizing willows, Salix barclayi and $S$. sitchensis, would rapidly give way to late successional species (e.g., Salix alexensis, Alnus, and Picea; Cooper 1939), S. barclayi and S. sitchensis continue to dominate the plots, with few to no late seral species established in the understory. It is worth noting that Q2, the only plot with Picea present, had the lowest Salix presence for the entirety of the first $50 \mathrm{yr}$ of its existence (Appendix S1: Table S2), likely due to exclusion by early and complete Dryas coverage (Chapin et al. 1994). In general, Salix were able to not only establish early but also maintain dominance after a century, in contrast to historical expectations (e.g., Cooper 1939) and spatial patterns in the West Arm of Glacier Bay, a pattern hypothesized to be driven by differences in wind direction, climate, or more bedrock exposure (Cooper 1931, Chapin et al. 1994). By following sites for $100 \mathrm{yr}$, rather than using inferences from chronosequences, this work confirms that canopy development does not follow a single timeline (rate) of stage development nor, for at least a century, a single compositional trajectory.

\section{Diversity}

Plot-level species richness increased rapidly over the first $\sim 50$ yr post-succession and slightly since (Fig. 3),

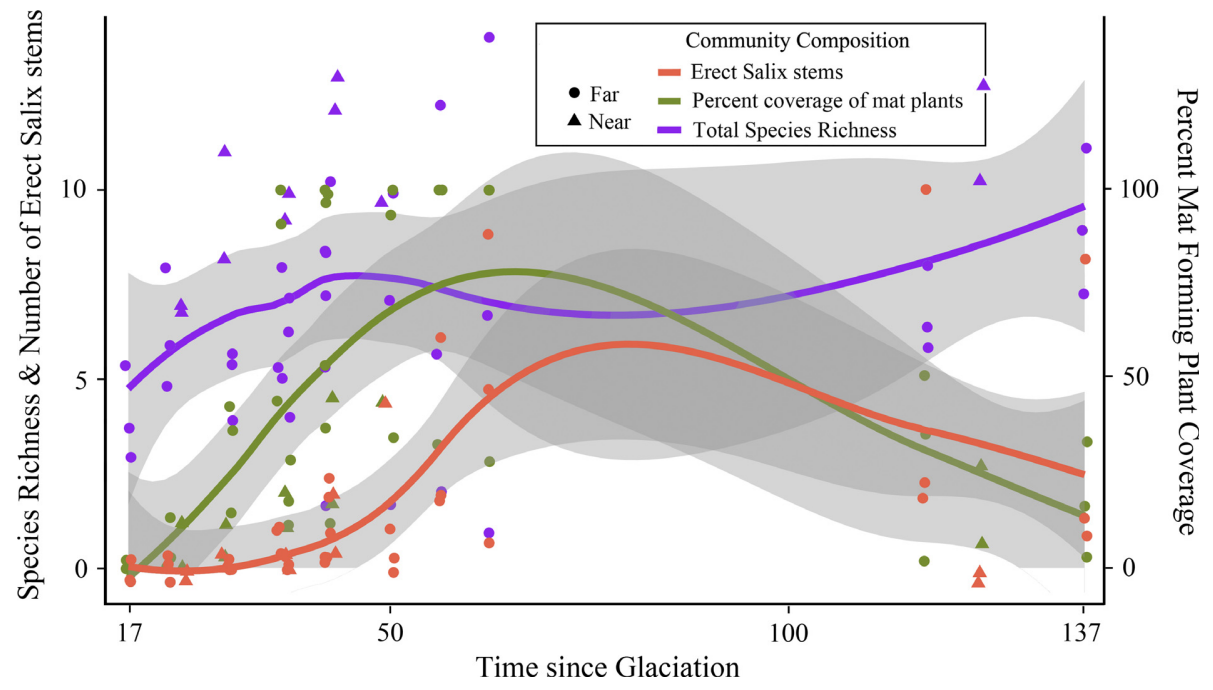

FIG. 3. Community development throughout the $100 \mathrm{yr}$ of observation. Points are individual observations of quadrats (jittered to avoid overlap); lines are loess smoothed trends. Symbols shape denote distance from potential seed sources after the Last Glacial Max (Table 1). Mat plants dominated from $\sim 20$ to 50 yr post-glaciation, followed by erect Salix stems. Salix continues to dominate most plots as larger individuals increase and the number of stems has declined. Species richness continues to accumulate. Moss species pooled for consistency with previous work. [Color figure can be viewed at wileyonlinelibrary.com] 


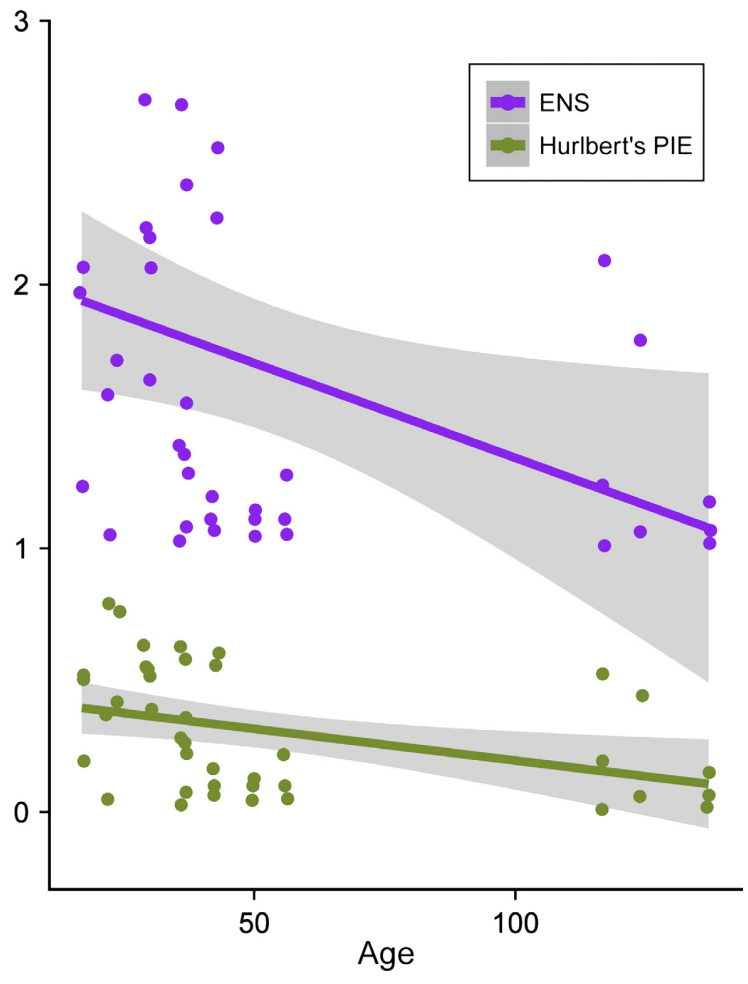

FIG. 4. Effective number of species (ENS) and Hurlbert's probability of interspecific encounter (PIE) per quadrat over time since exposure. PIE estimates the probability that two individuals pulled at random are different species and ranges from 0 to 1 . ENS is an index of the number of equally abundant species (i.e., a perfectly abundant community) required to achieve the same diversity value (PIE). Points represent each sampled quadrat at each observation time, illustrating variance in estimates. Line is simple linear regression for illustrative purposes; there is a significant downward trend (Spearman's $\rho, P<0.05$ ) in ENS and PIE over time since exposure. [Color figure can be viewed at wileyonlinelibrary.com]

though composition has changed dramatically. Early successional dominants Dryas and Racomitrium gave way to increasing shrub species cover but also increased diversity of herbaceous and mat-forming species (Appendix S1:
Table S4). Hurlbert's PIE and the ENS have both declined with time (Spearman's $\rho, P<0.05$; Fig. 4) as the relative abundance of a few species increased and new, rare species became established. Although the number of rare species increased over time, increasing richness, their limited abundance is reflected in the low ENS values, which are adjusted to account for rare species' effect on community richness totals. Interestingly, the two plots closer to the mouth of Glacier Bay have had consistently higher species richness throughout the last century (Fig. 3). Assessments of landscape-scale species richness from the re-sampled rarefaction method also estimate an increase in species over time until mid-century, with a leveling off after that point, likely driven by canopy closure (Table 2). However, rarefaction analyses also indicate that plot sizes have not adequately captured the true species assemblage since approximately $40 \mathrm{yr}$ post-exposure (Appendix S1: Fig. S2). A complete list of species currently on the plots by percent cover can be found in Appendix S1: Table S4.

\section{Soil development}

There was no relationship between plot age and soil depth (total, litter layer, or developed soil, $P>0.05$ ). Rather, it appears that the differing successional pathways observed have resulted in heterogeneous soil depths (9-14 cm; Table 3). The deepest, Q2 (19.2 cm), is located directly under a rapidly growing Picea. Plot Q7, which had a shallow $6.7 \mathrm{~cm}$ depth, is on the edge of a narrow $(\sim 10 \mathrm{~cm})$ gully-like erosional pathway not present in 1916. While there was no trend between carbon concentrations and plot age $(P>0.05)$, nitrogen concentrations did increase with plot age, and overall $\mathrm{C}$ to $\mathrm{N}$ ratio decreased $(P<0.05$; Fig. 5). The two major N-fixing components of the community are Alnus and Dryas. Alnus only dominated two plots (Q7 and Q8, and it occurs in the community surrounding plot Q1 and Q6; personal observation), and $\mathrm{N}$ concentrations were similar between those locations. Nitrogen concentrations were lower on the plots still dominated by Salix (Q4 and 5).

TABLE 2. Plant community diversity estimates from rarefied re-sampling of pooled quadrat sample data over time since exposure.

\begin{tabular}{|c|c|c|c|c|c|c|}
\hline $\begin{array}{l}\text { Time since } \\
\text { exposure }(\mathrm{yr})\end{array}$ & $\begin{array}{c}\text { Total } \\
\text { no. Spp obs }\end{array}$ & $\begin{array}{c}\text { Mean } \\
\text { no. Spp obs }\end{array}$ & $\begin{array}{c}\text { Rarefied Mean } \\
\text { no. Spp }{ }_{\text {est }}\end{array}$ & $\begin{array}{c}\text { Rarefied } \\
\text { no. Spp } \text { est }_{\text {ener }} \mathrm{CI}^{\dagger}\end{array}$ & $\begin{array}{c}\text { Rarefied } \\
\text { no. Spp } p_{\text {est }} \text { Upper CI } \dagger\end{array}$ & $\mathrm{ACE}$ \\
\hline $17-37$ & 13 & 6 & 11 & 10 & 12 & 12 \\
\hline $22-42$ & 17 & 8 & 14 & 11 & 18 & 15 \\
\hline $30-50$ & 19 & 7 & 15 & 11 & 19 & 19 \\
\hline $36-56$ & 20 & 9 & 16 & 12 & 20 & 18 \\
\hline $117-137$ & 16 & 5 & 12 & 8 & 16 & 14 \\
\hline $117-137 \ddagger$ & 24 & 8 & 19 & 14 & 23 & 20 \\
\hline
\end{tabular}

Notes: Observed values are cumulative (Total $\mathrm{Spp}_{\mathrm{obs}}$ ) and average (Mean $\mathrm{Spp}_{\mathrm{obs}}$ ) estimates of richness across all quadrats over each time step. Rarefied richness values are estimates of the number of species likely to occur in larger samples from the same assemblage. Abundance-based coverage estimator (ACE) values account for rare species within the assemblage and are often a better estimate of asymptotic richness (Colwell et al. 2012).

$\dagger$ Mean estimated no. of species found in larger sample from same assemblage.

$\$$ Moss species separated out (pooled in all other analyses for consistency with Cooper and Lawrence datasets). 
TABLE 3. Soil depth per plot.

\begin{tabular}{lccc}
\hline \hline Quadrat & Duff depth $(\mathrm{cm})$ & Soil depth $(\mathrm{cm})$ & Total depth $(\mathrm{cm})$ \\
\hline Q1 & 4.6 & 5.1 & 9.7 \\
Q2 & 3.8 & 15.6 & 19.4 \\
Q3 & 5.1 & 9.3 & 14.4 \\
Q4 & 3.0 & 9.3 & 12.3 \\
Q5 & 2.5 & 6.8 & 9.3 \\
Q6 & 4.7 & 9.3 & 14.0 \\
Q7 & 2.5 & 4.5 & 6.7 \\
Q8 & 3.4 & 7.7 & 11.1 \\
\hline
\end{tabular}

Notes: Data is averaged from three locations per plot, extending from surface to glacial till. All data from 2016.

\section{Discussion}

A century ago, William S. Cooper established vegetation plots on recently deglaciated surfaces of known age, which now represent the longest permanent record of vegetation succession. While small in extent and limited in number, their value is still immense for their historical significance, the frequency of repeat visits, and as a check on current successional theory. Cooper originally established the plots with the idea that time since glaciation would best control the rate and pathways of primary succession (Cooper 1923), hence locating plots with variable time since glacial retreat (Table 1), in essence creating an "internal chronosequence." This idea was borne out by initial results - higher plant coverage, and frequency of Salix individuals in particular, were associated with the older plots.

Over the last $50 \mathrm{yr}$, however, the importance of time since glaciation differences seems to be overshadowed by the effects of space and stochastic species assemblage. Though the sample size is low, species richness is generally higher closer to the entrance to Glacier Bay (Q7 and

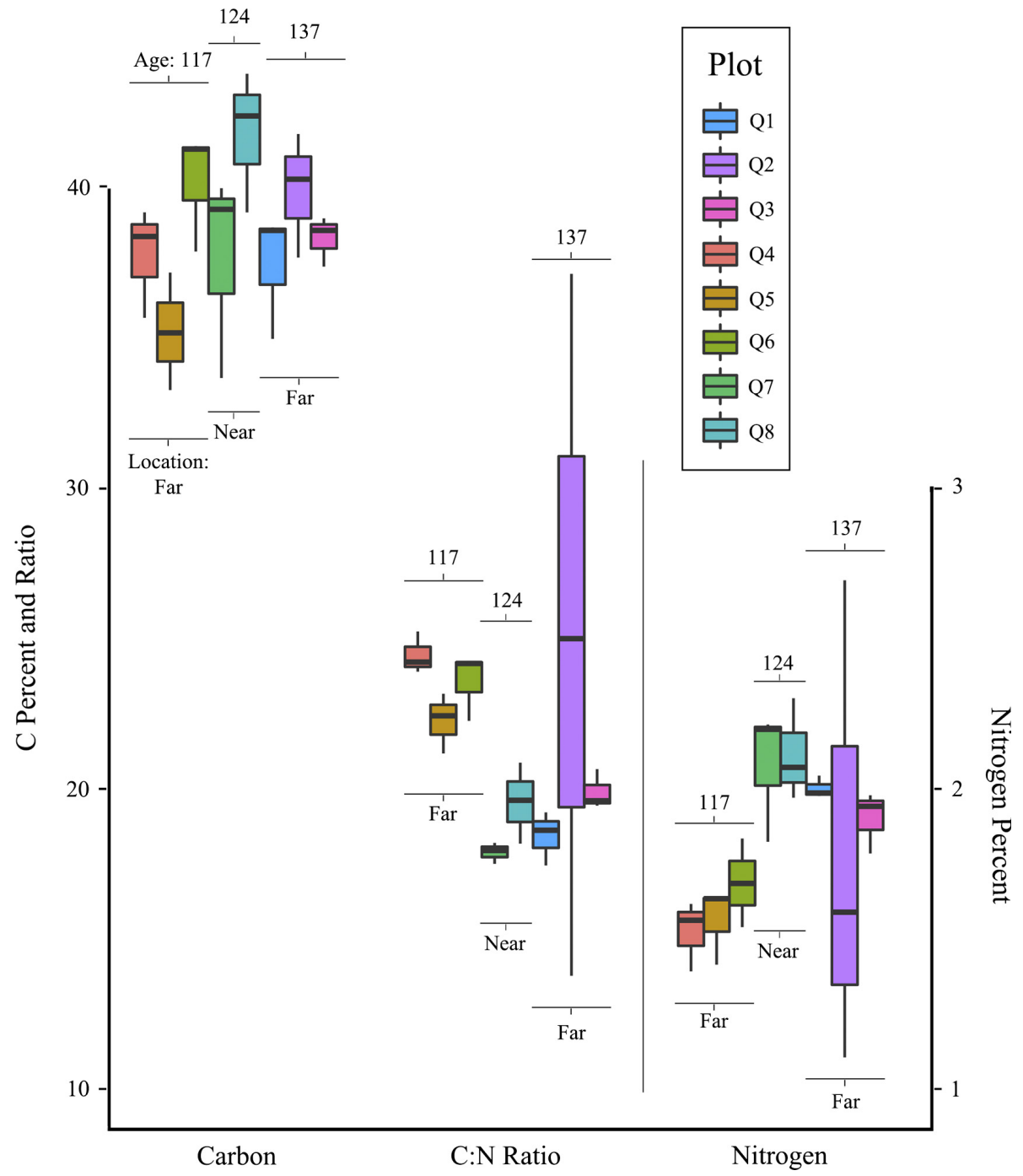

FIG. 5. Soil chemistry of the plots in 2016, ordered by time since glacial retreat (age). Location refers to place in the context of Glacier Bay (see Fig. 1). [Color figure can be viewed at wileyonlinelibrary.com] 
8), in the direction of incoming seed sources (Appendix S1: Table S4). An exception is Q1, far from the source of invading species but with relatively high species diversity. Q1 was the most heavily visited plot, and both Cooper and Lawrence repeatedly warned about potential for researchers to disseminate seed from other locations to the plots. Overall, succession (as a directional process) has proceeded differently than other parts of Glacier Bay, which generally observed a coniferous forest stage on plots of this age (though with substantial variability; Chapin et al. 1994, Fastie 1995).

The plots show high heterogeneity in terms of canopy coverage, community composition, and soil development despite the overall low diversity. They highlight the importance of early arrival of species in influencing subsequent successional pathways (e.g., the initial floristic composition hypothesis, Egler 1954). More recent work in Glacier Bay on succession is a useful contrast. That work (e.g., Chapin et al. 1994, Fastie 1995) has generally been conducted in the East Arm (see Fig. 1 inset), and suggested that successional patterns were strongly influenced by distance from seed sources; in some areas ice retreated faster than the advancing Picea forest could follow leading to Alnus dominance (Fastie 1995). While the Cooper plots are compositionally different from expectations based on that work, they offer support for the hypothesize mechanism that the pace of glacial retreat constrains community composition - it is simply exaggerated further in the West Arm of Glacier Bay, where the glaciers retreated even faster than in the East. Salix established early (Cooper 1921) and achieved early dominance due to their abundant seed rain, relatively light seeds, and rapid growth. In a similar setting where distance to seed source was not a factor (primary succession floodplains in interior Alaska), Walker et al. (1986) found that establishment by Alnus and Picea glauca (white spruce) was also limited (episodic) depending on seed production and dissemination. Helm and Allen (1995) similarly found that while all major woody species in their chronosequence study located at the Exit Glacier in Alaska were present in the "Barren Stage" in the immediate glacial forelands, Salicaceae spp. (Populus balsamifera, Salix alexensis, and $S$. sitchensis) were most abundant in early stages. Heavier seeded Alnus viridis var. sinuata did not become abundant until later stages. Likewise, the relatively fast retreat of glaciers in the West Arm of Glacier Bay, where Cooper's plots were located, appears to have allowed light, abundant, wind-dispersed Salix seeds to colonize the landscape early (Cooper 1921) and monopolize resources years before heavier seeded, slower-growing Alnus or Picea arrived (Appendix S1: Table S3). The resultant community is fundamentally different from the East Arm and much of the historically described successional communities, highlighting how spatial constraints on species establishment can influence subsequent biotic interactions and community dynamics for at least a century.

The early arrival of Salix species, contemporaneous with an important $\mathrm{N}$-fixing species (Dryas), allowed for early and continued Salix dominance through the end of the first century of monitoring. Dryas (which completely covered Q2 and 6 and mostly covered 3, 4, 7 and 8 by 1935 ) is self-limiting and generally not self-replacing. In contrast, the Salix canopy, litter layer, and its ability to reproduce vegetatively appear to preclude establishment of "later" successional species (e.g., Picea), arresting the process of succession (sensu Walker et al. 2010). The only plot without early Salix domination (Q2) is the only plot to have Picea presence currently. Later successional species like Picea and Tsuga are found scattered around the landscape as large, mature individuals, but expansion of those species appears to be quite limited spatially. There was only one Picea seedling on one plot (Q2, where Picea cover dominates), and few seedlings or saplings are seen off the plots. The general impression is one of an early (before 1950) cohort of "late successional" conifers (visible in Fig. 1B) that established early and grew rapidly but have generally failed to reproduce under the thick Salix canopy.

Similar to the canopy, it appears that nitrogen accumulation over the first $\sim 140 \mathrm{yr}$ of ecosystem development is more dependent upon species assemblage than time. Nitrogen accumulation is a process that can occur over centuries to millennia, and, as a result, has been almost exclusively studied via chronosequences (Jenny 1941, McLauchlan et al. 2014, Walker and Wardle 2014). In these plots, soil fertility differences are partially attributable to the different plot ages in addition to vegetative effects. Plots with Alnus had lower C:N ratios than similar aged plots in other studies (e.g., Crocker and Dickson 1957), supporting the hypothesis that the late Alnus establishment (due to spatial constraints) delayed that significant component of soil development. In plots without Alnus, C:N ratios were higher, more similar to very early soil development patterns where $\mathrm{N}$ is extremely limited (Crocker and Major 1955). If an Alnus stage does eventually occur in plots still dominated by Salix, then $\mathrm{N}$ concentrations will increase (lowering the $\mathrm{C}: \mathrm{N}$ ratio) on most plots, and the current condition represents a long delay from expected rates of soil formation (e.g., Crocker and Major 1955, Hobbie et al. 1998, Chapin et al. 1994). If there is no further Alnus colonization, a realistic future given the thick Salix coverage, than soils will likely not gain substantial further $\mathrm{N}$ stocks, which may have long-term implications for site productivity.

Although the highly variable glacial till and distribution of rocks and pore spaces makes soil sampling highly heterogeneous and absolute concentration measurements difficult (Chapin et al. 1994), the relationship between the long-term observations of plant succession and the $\sim 130$ yr old soils makes it possible to infer relative soil trajectories. Some attributes expected to converge (Walker et al. 2010), such as total soil organic matter and soil depth, are still diverging, with an over two-fold variation in soil depths between plots. Assuming that the conifer forest condition does represent the eventual future of this landscape, the observed variable soil depths 
and nutrient concentrations highlight the non-linear nature of initial soil development during succession. This provides observational evidence supporting the hypothesis that variable initial plant establishment and resultant soil nutrient heterogeneity may drive variable long-term conifer vigor later in succession (Fastie 1995).

Despite the small sample size and spatial extent, these plots provide a unique point of reference. They underscore the significance of species availability, competitive interactions, and, importantly, geographic location amongst the variety of ecosystem development drivers (Meiners et al. 2015). These plots also underline the variation possible even in a relatively small geographic area-expectations of a fairly rapid Dryas to Picea succession (Cooper 1923, Chapin et al. 1994) based on observations from other areas within Glacier Bay are not fulfilled, likely due to the competitive and geographic effects mentioned above (Fastie 1995). This does not fundamentally contradict previous research on succession at Glacier Bay, but refines it - while the species assemblages and timelines are different in different portions of the Bay, the likely mechanisms controlling those patterns are the same (spatial limitations on dispersal, subsequent domination by early successional species and competitive exclusion of later successional species).

Recent synthetic research by Walker et al. (2010) has suggested that chronosequences are useful for characteristics of communities that change in a linear fashion or converge with time, such as soil organic matter accumulation, but less suited for potentially divergent aspects of plant communities that are influenced more by priority effects or other mechanisms. Johnson and Miyanishi (2008) have argued that for dominant species composition (frequently called "stages of succession"), chronosequences are not useful in most cases as there is often no particular sequence required in the development of plant cover. Cooper's original plots can be used to test those expectations, at least for the first $137 \mathrm{yr}$ of community development. In the case of Glacier Bay, the linear and directional retreat of the glaciers led to important dispersal-based constraints on plant species establishment and thus community composition, soil development, and many other factors. The impact of this spatial constraint on community composition is evident not only when comparing these findings to prior work in the East Arm (e.g., Chapin et al. 1994) but also within this study in the "internal chronosequence" Cooper established. Unique to the Cooper plots is that the oldest sites are not the closest to available seed sources, avoiding the confounding effect of dispersal distance and plot age in the East Arm studies. On the Cooper plots, age has proved to be less predictive of community composition than spatial location. These results support criticism of naive interpretations of chronosequence research (e.g., as predicting specific community composition, absolute temporal patterns, or trajectories; problems summarized in Johnson and Miyanishi 2008). This applies even in low biodiversity systems, in contrast to expectations from Walker et al.
(2010). Over the first $137 \mathrm{yr}$ of succession, there is no single pathway of dominant vegetation development in Glacier Bay (as also concluded in Fastie 1995).

However, community biodiversity metrics (e.g., probability of interspecific encounters) did follow a relatively consistent trajectory across plots and time, despite major variation in the dominant canopy species (Fig. 4). This supports the hypothesis that convergence during succession depends on the level of organization consideredhighly variable at the level of individual species but more predictable when looking at composite metrics like species-trait diversity (Fukami et al. 2005) or ENS/PIE (here). This contrast highlights the need to avoid reliance on simplistic interpretations of chronosequences common in textbooks, but also the potential for theoretical community ecology research (less concerned with individual species) to work towards generalities.

The small sample size of these original plots must be kept in mind, however. Although size was sufficient early in the plot networks' history (Appendix S1: Fig. S2), Cooper began raising concerns about the plot sizes as early as 1935, and the rarefaction analysis validates this worry. Actual species richness is likely significantly higher than estimated for several points in time, including Cooper's later expeditions (e.g., Cooper 1939; Appendix S1: Fig. S2). Nonetheless, the long-term data both within the plots and in the rich set of ancillary notes and photographs from the initial publications provides an excellent foundation for future work and expansion in the fundamental and ever-developing study of plant community succession.

\section{Conclusion}

In Glacier Bay, the fine-scale post-glacial plant community has now been closely monitored for $100 \mathrm{yr}$ of development. The data derived from these plots both support the general theories developed by Cooper and his students (including Daubenmire, Oosting, Egler, and Marr, all significant in the development of the field of ecology) and validate more recent research (e.g., regional expansion of the forest, Buma and Barrett 2015). It also provides an important check on existing theory by highlighting the significance of early establishment and longterm dominance of early successional species and the importance of contingency in community development. Chronosequence methodologies are often the only option for assessment. But when patterns are found in chronosequence research, there is little to inform the researcher of the pathway taken to those patterns, and preconceived expectations may subtlety bias interpretations, leading to incorrect conclusions (as described in Johnson and Miyanishi 2008, Fastie 1995). The 100-yr record of these plots, including species composition, spatial relationships, cover, and observed interactions between species provides a powerful view of long-term primary succession. These plots formed the foundational data for succession during the origination of the science 
of ecology, and continue to inform the science today. Future monitoring and expansion of this unique study will continue to build on that legacy.

\section{ACKNOWLEDGMENTS}

Funding was provided by the National Geographic Society (Waitt Grant, W399-15) and the University of Alaska Southeast. Glacier Bay National Park provided logistical support. Thank you to the archives at the University of Minnesota for preliminary map gathering, Glenn Juday for suggestions on the potential location of Q8. Sarah Stehn of the National Park Service provided assistance in bryophyte identification and two reviewers provided excellent comments.

\section{Literature Cited}

Billings, W. D. 1938. The structure and development of old field shortleaf pine stands and certain associated physical properties of the soil. Ecological Monographs 8:437-500.

Buma, B., and T. Barrett. 2015. Signs of disturbance disequilibrium and directional change in the world's largest temperate rainforest. Global Change Biology 21:3445-3454.

Castle, S. C., Y. Lekberg, D. Affleck, and C. C. Cleveland. 2016. Soil abiotic and biotic controls on plant performance during primary succession in a glacial landscape. Journal of Ecology. https://doi.org/10.1111/1365-2745.12615

Chapin, F. S., L. R. Walker, C. L. Fastie, and L. C. Sharman. 1994. Mechanisms of primary succession following deglaciation at Glacier Bay, Alaska. Ecological Monographs 64:149-175.

Chase, J. M., and T. M. Knight. 2013. Scale-dependent effect sizes of ecological drivers on biodiversity: Why standardised sampling is not enough. Ecology Letters 16(s1):17-26.

Clements, F. E. 1916. Plant succession: an analysis of the development of vegetation. No. 242. Carnegie Institution of Washington Press of Gibson Brothers, Washington DC, USA.

Colwell, R. K. 2009. Biodiversity: concepts, patterns, and measurement. Pages 257-263. The Princeton guide to ecology.

Colwell, R. K. 2013. EstimateS: statistical estimation of species richness and shared species from samples. Version 9. User's guide and application. http://purl.oclc.org/estimates

Colwell, R. K., A. Chao, N. J. Gotelli, S.-Y. Lin, C. X. Mao, R. L. Chazdon, and J. T. Longino. 2012. Models and estimators linking individual-based and sample-based rarefaction, extrapolation, and comparison of assemblages. Journal of Plant Ecology 5:3-21.

Colwell, R. K., C. X. Mao, and J. Chang. 2004. Interpolating, extrapolating, and comparing incidence-based species accumulation curves. Ecology 85:2717-2727.

Cooper, W. S. 1923. The recent ecological history of Glacier Bay, Alaska: permanent quadrats at Glacier Bay: an initial report upon a long-period study. Ecology 4:355-365.

Cooper, W. S. 1931. A third expedition to Glacier Bay, Alaska. Ecology 12:61-95.

Cooper, W. S. 1939. A fourth expedition to Glacier Bay, Alaska. Ecology 20:130-155.

Cowles, H. C. 1899. The ecological relations of the vegetation on the sand dunes of Lake Michigan. Part I. Geographical relations of the dune floras. Botanical Gazette 27:95-117.

Cowles, H. C. 1901. The physiographic ecology of Chicago and vicinity; a study of the origin, development, and classification of plant societies (concluded). Botanical Gazette 31:145-182.

Cowles, H. C. 1911. The causes of vegetational cycles. Annals of the Association of American Geographers 1:3-20.

Crocker, R. L., and B. A. Dickson. 1957. Soil development on the recessional moraines of the Herbert and Mendenhall
Glaciers, south-eastern Alaska. The Journal of Ecology 45:169-185.

Crocker, R. L., and J. Major. 1955. Soil development in relation to vegetation and surface age at Glacier Bay, Alaska. The Journal of Ecology 43:427-448.

Darwin, C. 1859. On the origin of the species by natural selection. J. Murray, London, UK.

Dauby, G., and O. J. Hardy. 2012. Sampled-based estimation of diversity sensu stricto by transforming Hurlbert diversities into effective number of species. Ecography 35:661-672.

Egerton, F. N. 2015. History of ecological sciences, part 54: succession, community, and continuum. Bulletin of the Ecological Society of America 96:426-474.

Egler, F. E. 1954. Vegetation science concepts. I. Initial floristic composition, a factor in old-field vegetation development. Vegetatio 4:412-417.

Fastie, C. L. 1995. Causes and ecosystem consequences of multiple pathways of primary succession at Glacier Bay, Alaska. Ecology 76:1899-1916.

Frazer, G. W., C. D. Canham, and K. P. Lertzman. 1999. Gap Light Analyzer (GLA), Version 2.0: Imaging software to extract canopy structure and gap light transmission indices from true-colour fisheye photographs, users manual and program documentation. Pages 36. Simon Fraser University, Burnaby, British Columbia, Canada, and the Institute of Ecosystem Studies, Millbrook, New York, USA.

Fukami, T., T. M. Bezemer, S. R. Mortimer, and W. H. van der Putten. 2005. Species divergence and trait convergence in experimental plant community assembly. Ecology Letters 8:1283-1290.

Gleason, H. A. 1917. The structure and development of the plant association. Bulletin of the Torrey Botanical Club 44:463-481.

Gotelli, N. J., and R. K. Colwell. 2001. Quantifying biodiversity: procedures and pitfalls in the measurement and comparison of species richness. Ecology Letters 4:379-391.

Harmon, M. E., and R. J. Pabst. 2015. Testing predictions of forest succession using long-term measurements: $100 \mathrm{yrs}$ of observations in the Oregon Cascades. Journal of Vegetation Science 26:722-732.

Helm, D. J., and E. B. Allen. 1995. Vegetation chronosequence near Exit Glacier, Kenai Fjords National Park, Alaska, USA. Arctic and Alpine Research 27:246-257.

Hobbie, E. A., S. A. Macko, and H. H. Shugart. 1998. Patterns in $\mathrm{N}$ dynamics and $\mathrm{N}$ isotopes during primary succession in Glacier Bay, Alaska. Chemical Geology 152:3-11.

Hurlbert, S. H. 1971. The nonconcept of species diversity: a critique and alternative parameters. Ecology 52:577-586.

Jenny, H. 1941. Factors of soil formation. Dover Publications, Inc., New York, New York, USA.

Johnson, E. A., and K. Miyanishi. 2008. Testing the assumptions of chronosequences in succession. Ecology Letters 11:419-431.

Jost, L. 2006. Entropy and diversity. Oikos 113:363-375.

Lawrence, D. B. 1948. A fifth expedition to Glacier Bay, Alaska, and a summary of 25 years of observation. Unpublished, last revised in 1988. University of Minnesota Archives.

Lawrence, D. B., R. E. Schoenike, A. Quispel, and G. Bond. 1967. The role of Dryas drummondii in vegetation development following ice recession at Glacier Bay, Alaska, with special reference to its nitrogen fixation by root nodules. Journal of Ecology 55:793-813.

McLauchlan, K. K., et al. 2014. Reconstructing disturbances and their biogeochemical consequences over multiple timescales. BioScience 64:105-116.

Meiners, S. J., M. W. Cadotte, J. D. Fridley, S. T. A. Pickett, and L. R. Walker. 2015. Is successional research nearing its 
climax? New approaches for understanding dynamic communities. Functional Ecology 29:154-164.

Pearson, R. G., S. J. Phillips, M. M. Loranty, P. S. Beck, T. Damoulas, S. J. Knight, and S. J. Goetz. 2013. Shifts in Arctic vegetation and associated feedbacks under climate change. Nature Climate Change 3:673-677.

Pickett, S. T. A. 1989. Space-for-time substitutions as an alternative to long-term studies. Pages 110-135 in G. E. Likens, editor. Long-term studies in ecology. Springer, New York, New York, USA

Shepherd, A., et al. 2012. A reconciled estimate of ice-sheet mass balance. Science 338:1183-1189.
Tilman, D. 1985. The resource-ratio hypothesis of plant succession. American Naturalist 125:827-852.

Walker, L. R., and D. A. Wardle. 2014. Plant succession as an integrator of contrasting ecological time scales. Trends in Ecology \& Evolution 29:504-510.

Walker, L. R., D. A. Wardle, R. D. Bardgett, and B. D. Clarkson. 2010. The use of chronosequences in studies of ecological succession and soil development. Journal of Ecology 98:725-736.

Walker, L. R., J. C. Zasada, and F. S. Chapin. 1986. The role of life history processes in primary succession on an Alaskan floodplain. Ecology 67:1243-1253.

\section{SUPPORTING INFORMATION}

Additional supporting information may be found in the online version of this article at http://onlinelibrary.wiley.com/doi/ 10.1002/ecy.1848/suppinfo 